\title{
FORUM
}

Submitted 01.08.2019. Approved 08.02.2019

Evaluated through a double-blind review process. Guest Scientific Editors: Delane Botelho e Leandro Angotti Guissoni

Original version

DOI: http://dx.doi.org/10.1590/So034-759020200104

\section{CONSUMERS' KNOWLEDGE, MAXIMIZING TENDENCIES, AND POST-DECISION INFORMATION SEARCH}

\author{
Conhecimento do consumidor, tendência à maximização e a busca de informação \\ após decisões
}

\section{Conocimiento de los consumidores, tendencia a la maximización y la búsqueda de información posterior a decisiones}

\begin{abstract}
Nowadays consumers have more previous knowledge about products and services before making decisions. This study sheds light on the effects of consumers' previous knowledge on post-decision information search. Previous studies argue that cognitive dissonance and feelings of regret or dissatisfaction elicit this search. However, we show through one experimental and two correlational studies that this view is incomplete. Our findings indicate that knowledgeable consumers search for more information at the post-decision stage, even when the decision cannot be modified. This main effect is stronger (weaker) for maximizers (satisficers). Also, cognitive dissonance affects the postdecision information search behavior. Therefore, we suggest a new variable, consumers' previous knowledge, for consideration in the post-decision information search model.
\end{abstract}

KEYWORDS I Consumers' previous knowledge, information search behavior, post-decision stage, maximizing tendencies, cognitive dissonance.

\section{RESUMO}

Consumidores têm mais conhecimento prévio ao tomarem decisões. Este estudo mostra os efeitos desse conhecimento na quantidade de informação buscada após a tomada de decisão. Segundo a literatura, variáveis como dissonância cognitiva e sentimentos de arrependimento e insatisfação predizem essa busca. Porém, por meio de um experimento e dois estudos correlacionais, mostramos que essa visão está incompleta. Nossos achados indicam que consumidores com maior conhecimento prévio sobre determinado produto buscam mais informação após tomarem uma decisão, mesmo quando esta não pode ser modificada. Ainda, esse efeito é intensificado (minimizado) para pessoas com tendência à maximização (satisficers). Mostramos que não somente variáveis como dissonância cognitiva afetam o comportamento de busca de informação após decisões, mas que o nível de conhecimento prévio que consumidores têm sobre o produto também pode afetar tal busca. Logo, sugerimos uma nova variável para o modelo de busca de informação após decisões.

PALAVRAS-CHAVE / Conhecimento prévio do consumidor, busca de informação, pós-decisão, tendência à maximização, dissonância cognitiva.

\section{RESUMEN}

CRISTIANE PIZZUTTI DOS SANTOS ${ }^{2}$

cpsantos@ea.ufrgs.br

ORCID: 0000-0003-4188-5418

1 Pontifícia Universidade Católica do Rio Grande do Sul, Escola de Negócios, Porto Alegre, RS, Brazil

2Universidade Federal do Rio Grande do Sul, Escola de Administração, Porto Alegre, RS, Brazil

Los consumidores tienen más conocimiento previo antes de tomar decisiones. Este estudio presenta los efectos de ese conocimiento sobre la cantidad de información buscada posterior a la decisión. Según la literatura anterior, variables como disonancia cognitiva y sentimientos de arrepentimiento o insatisfacción provocan esta búsqueda. No obstante, a través de un experimento y dos estudios correlacionales, demostramos que esta visión es incompleta. Nuestros hallazgos sugieren que los consumidores con mayor conocimiento previo buscan más información después de tomar una decisión, incluso cuando está ya no se puede modificar. Además, este efecto es más fuerte (más débil) para los consumidores con tendencias maximizadoras altas (bajas). También mostramos que no solo variables como disonancia cognitiva afectan el comportamiento de búsqueda de información posterior a la decisión, sino que el nivel de conocimiento previo que los consumidores tienen sobre el producto también puede afectar dicha búsqueda. Finalmente, sugerimos una nueva variable para el modelo de búsqueda de información después de la decisión.

PALABRAS CLAVE / Conocimiento previo, Búsqueda de información, Posdecisión, Maximización, Disonancia cognitiva. 


\section{INTRODUCTION}

Collectively, 264 million US smartphone users view their devices 12 billion times per day (Deloitte, 2017), Brazilians alone spend 9 hours per day on the Internet (Kemp, 2018). These statistics indicate that the tools to access and acquire information are part of consumers' daily lives (Dholakia, Zwick, \& Denegri-Knott, 2013). For instance, consumers often engage in showrooming because they can easily look up information (Mehra, Kumar, \& Raju, 2017). Consequently, they become more knowledgeable about the available options and product features before making decisions (Dholakia et al., 2013).

Since information search still occurs after purchasing, it affects consumers' perceptions about their purchases (Teodorescu, Sang, \& Todd, 2018). However, researchers and marketers have been neglecting this behavior. Researchers focus mainly on behaviors such as word of mouth (e.g., Chu \& Kim, 2011; Hennig Thurau, Gwinner, Walsh, \& Gremler, 2004), consumer satisfaction, and feelings of regret (e.g., Lee \& Kim, 2008; Wirtz, Matilla \& Tan, 2007; Zeelenberg \& Pietres, 2007) when they investigate consumers' behavior at the post-decision stage. The few studies on post-decision information search mention that this search is primarily driven by cognitive dissonance and feelings of regret/ dissatisfaction (Oliver, 2014; Shani \& Zeelenberg, 2007). However, we claim that this view is incomplete as researchers do not consider consumers' previous knowledge in their post-decision information search models. The effect of consumers' previous knowledge on information search has already been explored for the initial stages of the customer journey (Hadar, Sood, \& Fox, 2013; Carlson, Vincent, Hardesty, \& Bearden, 2009; Brucks, 1985). However, to the best of our knowledge, prior studies have not extended this effect to a post-decision context.

This study addresses this gap in the literature by exploring the effect of consumers' previous knowledge at the pre-purchase stage on post-decision information search. Also, we present an interaction between consumers' previous knowledge and maximizing tendencies. We achieve this objective while controlling for cognitive dissonance and (dis)satisfaction as predictors of postdecision information search. Across three studies (one experiment and two correlational studies), we show that knowledgeable consumers search for more information the post-decision phase, even when they cannot change their decisions, because they can easily access information and their knowledge makes the search an easier task (Dholakia et al., 2013; Brucks, 1985). High levels of maximizing tendencies strengthen this effect. Additionally, cognitive dissonance has a significant effect on post-decision information search, and satisfaction does not.
Our study has several theoretical contributions. First, it sheds light on a new predictor of post-decision information search, the consumer's previous knowledge, updating the literature on this topic. This new predictor is in tune with an important phenomenon, characterized by the dramatic increase in consumers' knowledge through the widespread access of information (Dholakia et al., 2013). Second, to the best of our knowledge, we present a new interaction effect between previous knowledge and maximizing tendencies on post-decision information search, thus advancing the literature on maximizing tendencies as well. Few studies have investigated the effects of this trait on consumer behavior in the post-decision stage (Ma \& Roese, 2014). Third, this research explores the role of cognitive dissonance, which, so far, has not been empirically tested, even though Donelly and Ivancevich (1970) and Oliver (2014) state it to be an important driver of post-decision information search. Fourth, based on Lemon and Verhoef (2016)'s claim, we analyze consumer behavior through the link between two different stages of their journey: the pre- and post-decision phases. Thus, we present a more complete view of consumer behavior during the decision-making process.

For marketers, we elucidate the relevant effect of consumers' knowledge that increases the post-decision information search, and where consumers look up information at the post-decision stage. Companies usually invest less effort in the post-decision phase (Brega, 2018), and hence may lose the opportunity to diminish back-out behaviors and reinforce consumer choice (Donelly \& Ivancevich, 1970; Oliver, 2014). If companies understand and invest in this phase, they could increase their capabilities to create a "loyalty loop" (Brega, 2018). Helping marketers know more about consumers' information search behavior at the post-decision stage, and which variables affect this behavior, may help business companies to get the loyalty loop.

\section{THEORETICAL BACKGROUND}

\section{Consumers' previous knowledge}

The decision-maker's previous knowledge attracts the attention of researchers in different areas (Bettman \& Park, 1980; Brucks, 1985; Hadar et al. 2013). In this work, we comply with Brucks' approach (1985), which states that previous knowledge consists of information stored in individuals' memories in a specific moment. In our case, this knowledge is the knowledge consumers hold before decision-making. In consumption settings, previous knowledge would reflect an individual's degree of knowledge of 
brand names, usage procedures, and product features, among other attributes (Carlson et al., 2009).

Previous knowledge can be categorized into types: objective and subjective. Objective knowledge is the knowledge that is truly stored in an individual's memory. This knowledge depends on the consumer's actual ability to evaluate and use a product (Alba \& Hutchinson, 2000). When measuring objective knowledge, researchers might test subjects in a focal topic. Alternatively, researchers try to keep the objective knowledge constant to all participants to avoid confounds produced by such knowledge (Brucks, 1985). They can do this by using an unknow product and giving the same information about this product to the participants, for example (Brucks, 1985; Alba \& Hutchinson, 2000).

Subjective knowledge refers to a process in which an individual scans her memory for cues to evaluate her level of knowledge concerning a certain domain (Park, Monthersbaugh, \& Feick, 1994). This knowledge is built on the information an individual thinks she has stored in memory (Hadar et al., 2013). It is conventionally measured using items that request individuals to report the knowledge they believe they hold about a focal topic (Hadar et al., 2013).

Though many researchers have used subjective knowledge measures in their studies (Brucks, 1985; Hadar et al. 2013), there is some concern about their effectiveness as a proxy for objective knowledge. Particularly, Carlson et al. (2009) and Brucks (1985) suggest that self-confidence influences subjective knowledge measures because individuals may overestimate (or underestimate) their knowledge depending on their confidence. However, some critics argue that self-reported knowledge often approximates actual knowledge (Alba \& Hutchinson, 2000). Carlson et al. (2009) demonstrated through a meta-analysis that subjective and objective knowledge are significantly and positively correlated.

An important issue for studies that analyze the effect of previous knowledge on information search is knowledge calibration, which reflects the agreement between objective and self-assessed knowledge (Alba \& Hutchinson, 2000; Carlson et al., 2009). Considering this discussion, the studies presented herein investigated both objective and subjective previous knowledge.

\section{Consumers' previous knowledge and information search}

Knowledge is a key concept in information processing research (Raju et al., 1995) There exists a traditional stream of research that particularly explores the effects of consumers' previous knowledge on information search at the initial stage of the customer journey. These studies have found positive as well as negative relationships between these two variables (Hadar et al., 2013; Carlson et al., 2009; Brucks, 1985; Kiel \& Layton, 1983). Positive effects occur because knowledgeable individuals perceive the processing of new information to be an easier task (Carlson et al. 2009; Punj \& Staelin 1983). Consequently, they may formulate more questions related to the focal domain and search for more information to answer their own questions. Furthermore, high levels of knowledge increase the benefits of new information (Brucks, 1985).

Conversely, researchers who found negative effects justify their results by arguing that knowledgeable individuals know more about the attributes of available options. Thus, they do not need to acquire more external information (Brucks, 1985). Although Bettman and Park (1980) explained this apparent contradiction (i.e., the existence of both negative and positive effects) as an inverted U-shaped relationship, other authors have found significant linear effects in prior inquiry (e.g., Brucks, 1985; Hadar et al., 2013; Kiel \& Layton, 1983). Because the literature favors the positive effect (see Carlson et al., 2009; Hadar et al., 2013), we follow the logic that knowledge increases the information search.

Studies on the relationship between consumer's previous knowledge and information search have focused on the information search that occurs prior to the final decision (Brucks 1985; Hadar et al., 2013). However, consumers still search for information after finalizing their choices (Teodorescu et al., 2018) and the knowledge they have acquire before purchasing might affect this search as well. Their knowledge might increase post-decision information search because knowledgeable consumers have better awareness of where they can search for information; they can also process new information easier than non-knowledgeable consumers (Brucks, 1985).

Studies on post-decision information search have listed two main predictors of such behavior: cognitive dissonance and feelings of regret/dissatisfaction (see Donelly \& Ivancevich, 1970; Ehrlich, Guttman, Schönbach, \& Mills, 1957; Oliver, 2014; Shani \& Zeelenberg, 2007;). For instance, Ehrlich et al. (1957) found that consumers sought post-decision information to confirm their choices. The authors argumentatively used the cognitive dissonance theory to explain this behavior. Their perspective assumed that consumers search information after deciding to minimize their experience of dissonance. Nevertheless, these authors did not empirically explore the effect of cognitive dissonance. Likewise, Donelly and Ivancevich (1970) showed that consumers did not desire to switch their cars when they had information about their purchased cars. This information 
reinforced consumers' decisions, minimizing cognitive dissonance. However, the authors did not empirically test the role of cognitive dissonance either. Finally, Shani and Zeelenberg (2007) showed that feelings of regret or dissatisfaction motivate individuals to either acquire or avoid more information after purchasing.

Cognitive dissonance and feelings of regret/dissatisfaction are elicited during the post-decision stage of the consumer journey. However, consumers might not be affected only by the variables emerging at this stage after making their decisions since variables that influence consumer behavior during the initial stage of the customer journey still influence the end of this journey (Lemon \& Verhoef, 2016). In fact, the costumer journey stages are linked, even though researchers in consumer behavior treat them as isolated stages (Lemon \& Verhoef, 2016). Thus, we propose that consumers' previous knowledge, acquired at the pre-decision stage, increases post-decision information search:

$\mathrm{H}_{1}$ : The knowledge consumers hold before making their final decision will increase post-decision information search.

\section{Interaction between consumers' previous knowledge and maximizing tendencies}

Although the limited information-processing capacities of individuals make perfect maximization impossible (Simon, 1956), studies have shown that some individuals have higher maximizing tendencies than others (e.g., Goldsmith, Roux, \& Ma, 2018; Luan \& Li, 2017). Maximizers are usually more engaged with their decisions (lyengar, Wells, \& Schwartz, 2006). More than satisficers, they exhaustively engage in the decision-making process, by searching information and checking as many as available options they can, because they want to choose the best option (lyengar et al., 2006).

Therefore, we propose that maximizing tendencies influence the effect of consumers' previous knowledge on postdecision information search. Assuming a positive relationship between previous knowledge and post-decision information search $\left(\mathrm{H}_{1}\right)$ and predicting a positive relationship between maximization and need for more information, we infer that maximizers are more likely to use their previous knowledge to its full extent as a base for information search. Therefore, we propose that the effect of previous knowledge is intensified, or facilitated, by the "natural" maximizer's tendency to search more information. In contrast, satisficers have pre-defined parameters to judge when an option is satisfactory, or not, before making the final decision (lyengar et al., 2006). When satisficers find an option that fits within these parameters, they cease the search and assume that the benefit of further investing in maximizing their choice does not pay off (lyengar et al., 2006). Therefore, the more "satisficer" a consumer is, the weaker the positive relationship between her or his previous knowledge and post-decision information search. Thus, previous knowledge may decrease post-decision information search for low levels of maximizing tendencies. In tune with this, the more previous knowledge satisficers hold before the final decision, the more assured they may be that they made a choice that fits their parameters and that gathering more information after deciding will not benefit them.

H2: The effect of consumers' previous knowledge on the amount of post-decision information search will be stronger for maximizers than for satisficers.

In Study 1, we investigated the main effect proposed in $\mathrm{H}_{1}$ through an experimental study to understand the existence of the main effect and to increase the internal validity (Field \& Hole, 2003). In Study 2A and Study 2B, the correlational studies, we investigate the effects proposed by $\mathrm{H}_{1}$ and $\mathrm{H}_{2}$ in a more naturalistic setting to increase the external validity (Field \& Hole, 2003). Through these studies, we explore two moments during the post-decision stage: 1) when consumers have made a purchase but have not experienced the product yet (e.g., when they buy online and are waiting for the purchase delivery), and 2) when they have made a purchase and experienced it (e.g., when the get the product and have used it). In Study $2 \mathrm{~A}$, participants were requested to recall an online purchase they had not received yet, which is a common experience for consumers. For instance, Brazilians spent R\$ 2 bn in online purchases between March 2017 and March 2018 (Redação Forbes, 2018) and Americans spent US\$ 517.36 bn in 2018 (Ali, 2019). These consumers do not immediately experience their purchases after buying. Instead, they need to wait until the purchased product is delivered. During this period, they may search for more information about their purchases. In Study $2 \mathrm{~B}$, the participants recalled a purchase they had already experienced. In these studies, we tested the proposed interaction as well as the effect of cognitive dissonance and satisfaction.

\section{STUDY 1: THE MAIN EFFECT}

\section{Procedures}

We investigated the proposed main effect through a single factor experiment with data collected on Amazon Mechanical Turk. We manipulated the objective previous knowledge to maintain greater control under the participants' knowledge. Since subjective knowledge may be affected by individuals' self-confidence 
(Hadar et al., 2013), by manipulating objective knowledge we could minimize the effect of other variables on the participants' knowledge.

The participants were randomly assigned to one of two conditions (absence vs. presence of objective previous knowledge). They were informed that, during a task, they must choose a "brain game" that would improve reasoning. As an additional reward for participation, they would win a password to access the game of their choice on a brain games website for free for one month. All available options were games to improve reasoning or memory, namely, Towers of Hanoi, Rotation Game, and Logic Puzzles.

This deception served as the motivation for the gamechoosing component of the experiment. We presented participants to unusual games to avoid confounds arising from the their knowledge about and familiarity with the games before taking part in the study as we manipulated objective knowledge. The "absence of previous knowledge" group received only the names of the games and no other information about them before making their decision. On the other hand, the "presence of previous knowledge" group received an informative text about each game along with their names and a representative image. It is important to stress that by providing participants with (or with no) information about the games, contrary to asking participants to report how much they knew about them, we might have generated different levels of objective previous knowledge.

After choosing the game, we asked the participants to search for online information about the games from the list without imposing any limits on them. We measured the time each participant spent searching as a proxy of their levels of postdecision information search. To ensure the participants searched for information related to the game decision, they pasted the URLs they accessed during the activity in an appropriate space.

Furthermore, we controlled for the participants' prior experience with the games and for their involvement with the decision using two items adapted from Mittal (1989) (“How important was it to you to make a right choice of this decision?"-1: "Not at all” and 7: "Extremely important"; "In making your selection of this game, how concerned were you about the outcome of your choice?"-1: "Not at all concerned" and 7: "Very much concerned") (where, $r=.722$ ).

\section{Sample}

Eighty-three participants were recruited. They spent approximately 14 minutes (on average) to complete the task. For controlling the main effect, we asked participants to report the extent to which they rushed into the information search activity to finish the task quickly ("I did my online research as fast as I could to get over with this task as quick as possible"-1: "I strongly disagree" and 7: "I strongly agree"). Individuals who checked " 7 " were filtered out (seven cases). Moreover, to investigate participants' attention, we included an attention check item ("How important was this choice for you? Please ignore this question and go to the item below"). Six participants failed this attention check, and thus were removed. Finally, 13 participants were eliminated from the analysis. The final sample consisted of 70 participants (42 females; $\left.M_{\text {age }}=37.56\right)$.

\section{Manipulation check}

Since we manipulated the objective knowledge, to control for knowledge accumulated before the experiment, participants reported their experience with the games options we presented ("I am experienced with the games options I was presented"-1: "I strongly disagree" and 7: "Strongly agree"). The participants" experience with the games was low $(M=3.09, S D=1.631)$ and significantly below the midpoint of the scale, with $t(69)=$ 4.69 and $p<.001$. Additionally, they reported their experience with the game they chose ("I am experienced with the game I chose"-1: "I strongly disagree" and 7: "I strongly agree"). The participants did not have much experience with the game they chose $(M=2.96, S D=1.876)$, with the mean for this measure being significantly below the midpoint of the scale as well, with $t(69)=4.65$ and $p<.001$.

The manipulation check was measured with a single item ("The information about the games provided to make my game choice was sufficient to make a decision"-1: "I strongly disagree" and 7: "I strongly agree"). We expected the participants assigned to the "absence of previous knowledge" group to report lower levels of perceived information sufficiency. Indeed, they reported having a greater sensation of information insufficiency while making the game choice $(N=34, M=4.53, S D=1.813)$ than participants in the "presence of previous knowledge" group $(N=$ $36, M=5.50, S D=1.648)$, with $t(66)=-2.340$ and $p<.05$. We also conducted an analysis of covariance (ACOVA) to test if the effect of the experimental condition would remain when controlling for prior experience with the games of the list and prior experience with the chosen game. The effect of the experimental condition remained significant, whereas the potential covariates did not affect information sufficiency (experience with the games in the list, $F(1,66)=.506, n$.s; experience with the chosen game, $F(1$, 66) $=.711$, n.s). 


\section{Results}

An independent sample t-test was conducted. Individuals assigned to the "presence of previous knowledge" group $(M$ $=253.907$ seconds, $S D=107.108$ seconds) spent more time searching for information than individuals assigned to the "absence of previous knowledge" group $(M=140.106$ seconds, $S D=235.200$ ), with $t(68)=2.579, p<.05$, and $d=.62$ (see Graphic 1). A complementary ANCOVA showed that the effect was resilient when controlling for the participants' experience with the game. The item in which the participants reported their experience with the options available was nonsignificant, with $F(1,66)=.326, n . s$, as well as the item in which they reported their experience with the chosen game, with $F(1,66)=.013$, n.s. An ANCOVA also showed that involvement did not exert any effect, with $F(1,67)=.013$, n.s.

\section{Graphic 1. Bars with means per condition}

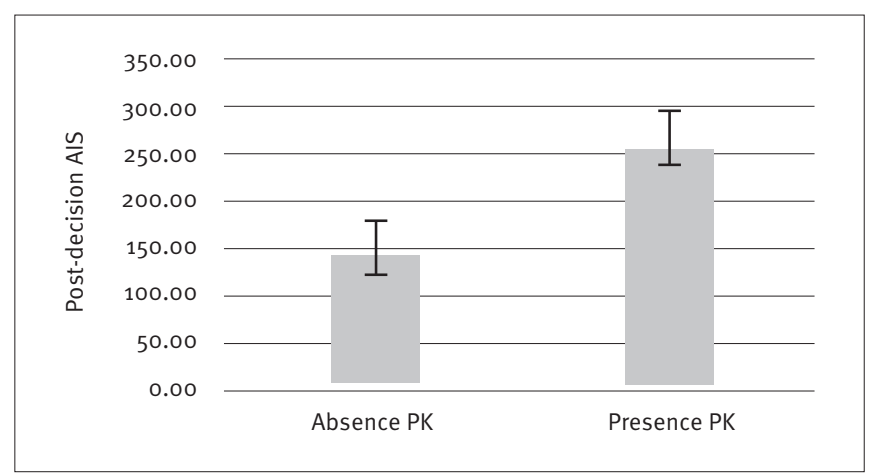

Errors bars represent \pm 1 SEM

PK: Prior Knowledge

\section{Discussion}

The results suggest that, even after a final decision was made (and could not be changed), participants exposed to previous knowledge dedicated more time to search for additional information after deciding than individuals who were not exposed to this knowledge. This result supports $\mathrm{H}_{1}$. A positive relationship between previous knowledge and post-decision information search may exist because individuals with knowledge about a focal domain can formulate more questions about a topic and can process new information using less effort (Brucks, 1985).

It is important to note that the study was conducted in a controlled setting, wherein the participants' decision-making involved purchases they had not desired in reality. Therefore, investigating the effect in a more realistic setting is important to validate the findings of Study 1 . To address this and test $\mathrm{H}_{2}$, we conduct Study $2 \mathrm{~A}$ and Study $2 \mathrm{~B}$, where we asked participants to recall a real purchase. Additionally, cognitive dissonance arises in specific situations, such as when individuals are responsible for their decisions and when a decision is important to them. This may, in turn, explain post-decision information search (Jones, 2002).

In Study 1, although the participants were responsible for their choices, accounting for cognitive dissonance effects would be inadequate as the participants' decision would not have been as important to them as a real purchase, for example. Importantly, we did not investigate their satisfaction with the decision because the participants did not played the game. Satisfaction may affect consumers' information search behavior (Shani \& Zeelenberg, 2007) as well.

Thus, Studies $2 \mathrm{~A}$ and $2 \mathrm{~B}$ cover the potential effect of the interaction between consumer's previous knowledge and maximizing tendencies and the role of cognitive dissonance. Study $2 \mathrm{~B}$ also addresses satisfaction as a covariate. Additionally, in the following studies, we investigated consumers' subjective previous knowledge to determine whether the effect we found in Study 1 occurs when consumers report the knowledge they think they had before purchasing a product.

\section{STUDY 2A: STUDY WITH A REAL PURCHASE, BEFORE EXPERIENCING THE PRODUCT}

\section{Procedure}

One hundred and fifty-one participants were recruited from Amazon Mechanical Turk. They recalled a recent, planned purchase they had made online, but had not had the opportunity to experience it yet. We asked them to complete the survey with the recalled purchase in mind. As the participants had not experienced the product, their postdecision information search behavior might have been higher than if they had already experienced it (Oliver, 2014). This allowed us to investigate the information search behavior in a more "extreme condition."

We explicitly asked the participants not to think of an everyday purchase (e.g., milk, bread, etc.), because such products tend to be purchased routinely. This way, everyday purchases might attenuate information search behavior regardless of previous knowledge and maximizing tendencies. In fact, they might not even generate experiences of strong cognitive dissonance. In this study, we did not investigate 
consumers' satisfaction as they had not experienced their purchases.

A single item measured consumers' subjective previous knowledge ("I had a lot of knowledge about this purchase before making my final decision"-1: "I strongly disagree" and 7: “I strongly agree") (Hadar et al., 2013). To measure postdecision information search, the participants used a slider scale to report how intensely they used specific approaches to find information about their purchase (where o: "I did not use this approach" and 100: "I used this approach very intensely"). We show some approaches (e.g., browsing websites or talking to friends/relatives) to them according with previous research on information search behavior. The sum of the scores that the participants assigned to the items served as our measure for information search. The maximizing tendencies were measured using 13 items from Schwartz et al. (2002) (1 = "I strongly disagree" and $7=$ "I strongly agree," with $a=.737$ ). The cognitive dissonance was measured through an adapted scale from Montgomery and Barnes (1993) with 11 items ( $1=$ “I strongly disagree” and $7=$ “| strongly agree," with $a=.843)$.

\section{Sample}

As in Study 1, an attention-check item served as the filter and led 50 cases to be removed from the sample. We also checked whether participants thought of an everyday purchase, but no further case removal was necessary for this criterion. The final sample included 101 participants (53 females, $M_{\text {age }}=36.86$ ).

\section{Results}

We conducted a hierarchical regression to determine how the introduction of different variables affected the results in the model (Field, 2013). In the full model, previous knowledge, maximizing tendencies, the interaction term, and cognitive dissonance were included as predictors. The data met the assumption of noncollinearity (previous knowledge: Tolerance $=.939, \mathrm{VIF}=1.065$; maximizing tendencies: Tolerance $=.887$ and $V I F=1.127$; cognitive dissonance: Tolerance $=.862$ and VIF $=1.160$ ) (Field, 2013). Postdecision information search was included as the dependent variable. Table 1 reports the order in which we included the variables.

Table 1. Summary of hierarchical regression analysis for variables predicting post-decision information search (Study 2A)

\begin{tabular}{|c|c|c|c|c|c|}
\hline Level 1 & & & .095 & .009 & -.001 \\
\hline Previous Knowledge (PK) & 6.826 & .949 & & & \\
\hline Previous Knowledge (PK) & 7.010 & .999 & & & \\
\hline Maximizing Tendency (MT) & 25.561 & 1.879 & & & \\
\hline Previous Knowledge (PK) & 12.707 & $1.883^{1}$ & & & \\
\hline Maximizing Tendency (MT) & 11.414 & .856 & & & \\
\hline$M T \star P K$ & 17.301 & $2.413^{*}$ & & & \\
\hline Cognitive Dissonance & 47.489 & $3.769^{\star \star}$ & & & \\
\hline
\end{tabular}

Note: ${ }^{1} p=.063 ;{ }^{*} p<.05 ;{ }^{* *} p<.01$. 
At level 1, previous knowledge was a nonsignificant predictor, with $F(1,99)=.900, n . s$; it accounted only for $0.9 \%$ of the variation in the degree of information search. Introducing maximizing tendencies and the interaction term explained an additional $7.8 \%$ of the variation. This change in $R^{2}$ was significant, with $F(2,97)=4.134$ and $p<.05$. The last addition, cognitive dissonance, explained an additional $11.8 \%$ of variation. Again, the $R^{2}$ change was significant, with $F(1,96)$ $=1.756$ and $p<.001$.

The full model (level 3) was significant, with $F(4,96)=$ 6.228 and $p<.001$, explaining $20.6 \%$ of information search. This model revealed a marginal significance effect of previous knowledge $(\beta=12.707, t=1.883$, and $p=.063)$. The result had the same direction as the result from Study 1 and was in tune with $\mathrm{H}_{1}$.

The models entered at levels 1 and 2 of the hierarchical regression analysis indicated nonsignificant effects of previous knowledge. This raises the possibility that previous knowledge might be sensitive to suppressors (Mackinnon, Krull, \& Lockwood, 2000). As this survey used a real purchase, the effect of previous knowledge might compete with that of several other factors that influence consumers' post-decision behavior (e.g., cognitive dissonance), which might be relevant for better adjustment of the regression. Not surprisingly, the effect of previous knowledge achieved its best significance level when the model included more predictors. The proposed interaction was statistically significant $(\beta=17.301, t=2.413$, and $p<.05)$ as well as the effect of cognitive dissonance $(\beta=$ $47.489, t=3.796$, and $p<.01$ ).

To estimate the effects of previous knowledge according to the maximizing tendencies values, we used the JohnsonNeyman technique to conduct a floodlight analysis (Spiller et al., 2013). We used model 1-PROCESS (Hayes, 2013) for this procedure. The results suggest that previous knowledge did not affect post-decision information search at the lowest levels of maximization. For maximization levels closer to the sample mean (maximizing tendencies $>.039$, mean-centered), the effects of previous knowledge were significant and positive, increasing in size as a function of maximizing tendencies. That is, the positive effects of previous knowledge tend to increase with the maximization tendencies (see Graphic 2).

We replicated the above study in Study 2B. However, this time, the participants were asked to recall a planned purchase they had already experienced. This way, we could explore the influence of satisfaction on information search behavior, and further determine whether the findings from Study $2 \mathrm{~A}$ are replicable.
Graphic 2. Floodlight graphic: The effect of the interaction on post-decision information search (Study $2 \mathrm{~A}$ )

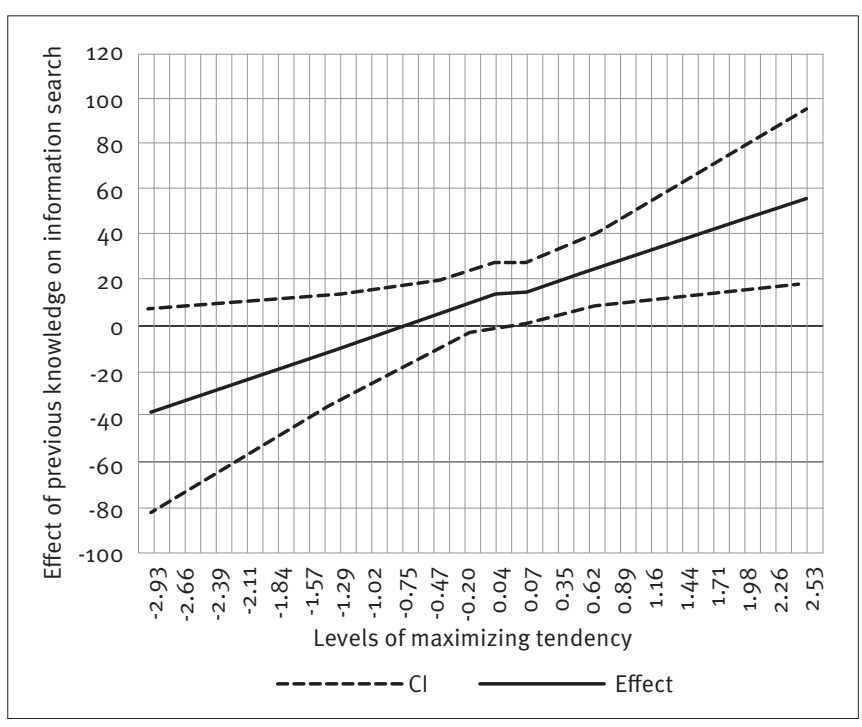

Note: Confidence Interval $(\mathrm{Cl})$ bands represent the "range" for $95 \% \mathrm{Cl}$.

\section{STUDY 2B: STUDY WITH A REAL PURCHASE, AFTER EXPERIENCING THE PRODUCT}

\section{Procedures}

One hundred and sixty participants from Amazon Mechanical Turk were recruited. The participants recalled a recent, planned purchase they had made and experienced. They accordingly completed a survey about their purchase. We measured previous knowledge, maximizing tendencies, and the post-decision information search as in Study 2A. However, to measure the participants' cognitive dissonance after their final decision, we used 21 items from Sweeney et al. (2000) (1: "I strongly disagree" and 7: "I strongly agree," with $a=.972$ ) because these authors presented an alternative to Montgomery and Barnes' (1993) scale (used in Study 2A). Satisfaction with the purchase was measured through 4 items adapted from Oliver (2014) (1: "I strongly disagree" and 7: "I strongly agree," with $a=.960)$.

\section{Sample}

We used the same filters from Study $2 \mathrm{~A}$ and removed eight cases from the sample for not following the instructions regarding the purchase to be recalled. We also filtered out participants who failed on the attention check ( 47 cases) by following the same procedure used in the previous studies. Fifty-five cases were removed, and the final sample consisted of 105 participants (65 females; $\left.M_{\text {age }}=36.96\right)$. 


\section{Results}

A correlation analysis tested the relationship between satisfaction and post-decision information search $(r=.068, n . s)$. The same procedure used in Study $2 \mathrm{~A}$ was conducted to investigate the effect of previous knowledge, maximizing tendency, their interaction and cognitive dissonance on post-decision information search. Table 2 reports the results from the hierarchical multiple regression analysis.

Table 2. Summary of hierarchical regression analysis for variables predicting post-decision information search (Study 2B)

\begin{tabular}{|c|c|c|c|c|c|}
\hline Level 1 & & & .156 & .024 & .015 \\
\hline Previous Knowledge (PK) & 14.478 & 1.605 & & & \\
\hline Previous Knowledge (PK) & 15.551 & 1.804 & & & \\
\hline Maximizing Tendency (MT) & 27.088 & 1.537 & & & \\
\hline Previous Knowledge (PK) & 16.982 & $2.044^{1}$ & & & \\
\hline Maximizing Tendency (MT) & 25.608 & 1.509 & & & \\
\hline$M T \star P K$ & 25.862 & $2.635^{\star *}$ & & & \\
\hline Cognitive Dissonance & 25.231 & $3.002^{\star \star}$ & & & \\
\hline
\end{tabular}

Note: ${ }^{1}=.0591 ;{ }^{* *} p<.01$

Previous knowledge alone did not contribute significantly to the model, with $F(1,103)=2.577, n . s$ (see level 1). The maximizing tendencies and the interaction term explained an additional $11.7 \%$ of variation in the information search, where the change in $R^{2}$ was statistically significant, with $F(2,101)=6.856$ and $p<.01$. The introduction of cognitive dissonance explained an additional $7.1 \%$ of variation. This change was also significant, with $F(1,100)=9.014$ and $p<.01$. According with the results from the hierarchical regression, the level 3 model is statistically significant, with $F(4,100)=6.728$ and $p<.001$, explaining $21.2 \%$ of the dependent variable. This model indicated a positive effect of previous knowledge with moderate significance $(\beta=16.982, t=2.044$, and $p=$ .0591) and a statistically nonsignificant effect of maximizing tendencies ( $\beta=25.608$ and $t=1.509, n . s)$. The proposed interaction had a statistically significant effect $(\beta=25.862, t=2.635$, and $p<.01)$, which is in tune with the findings from Study $2 \mathrm{~A}$.

A floodlight analysis using the Johnson -Neyman technique (Spiller et al., 2013) revealed that, for high levels of maximization (maximizing tendencies $>$.032, mean centered), the effects of previous knowledge were positive and increased as a function of the maximizing tendencies (see Graphic 3). This is in tune with the results from Study $2 \mathrm{~A}$. Conversely, the negative effects of previous knowledge on post-decision information search achieved moderate levels of significance at the lowest levels of maximization (maximizing tendencies $<-1.934$, mean centered). 


\section{Graphic 3. Floodlight graphic: The effect of the interaction} on post-decision information search (Study 2B)

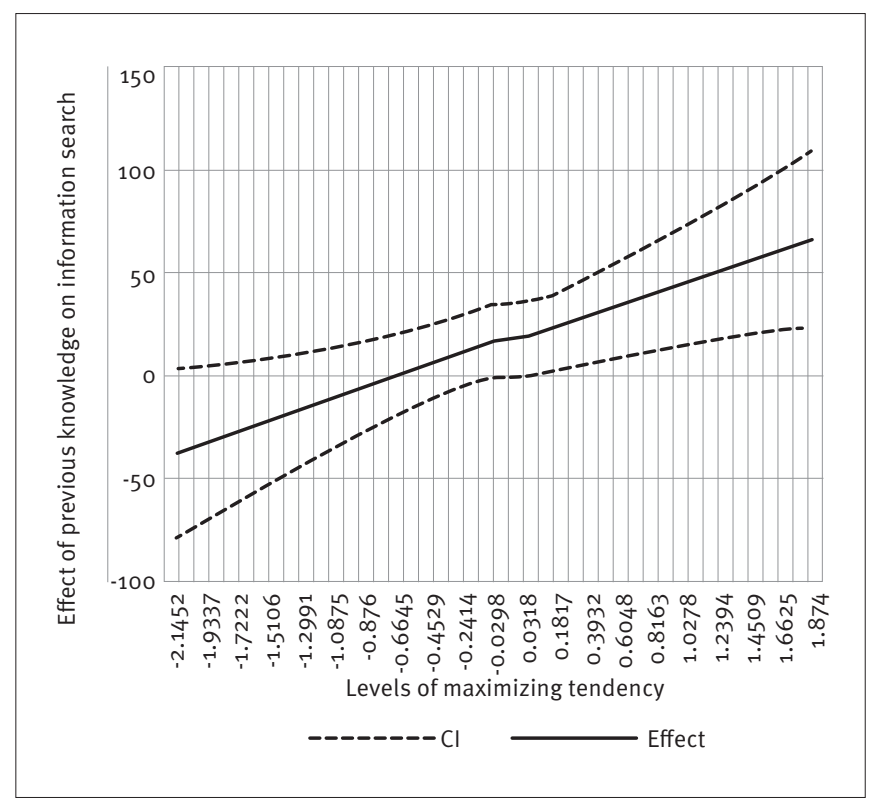

Note: Confidence Interval (CI) bands represent the "range" for $95 \% \mathrm{Cl}$.

Finally, since the participants indicated how intensely they searched for post-decision information in different sources, we explored the levels of intensity reported by them for each search of information we presented. Consumers searched by browsing online stores $(M=41.89)$; talking to friends/relatives $(M=36.00)$; reading online reviews $(M=33.31)$; visiting brick-and-mortar stores $(M=32.43)$; comparing the purchased option to equivalent choices of other consumers ( $M=29.57)$; attending to product information on social media $(M=18.00)$; browsing shopping windows ( $M=14.51)$; and clicking on online ads related to the chosen product $(M=10.19)$.

\section{Discussion}

Studies $2 \mathrm{~A}$ and $2 \mathrm{~B}$ show a positive and moderately significant effect of previous knowledge on post-decision information search when other variables were included in the model. The direction of the effect of previous knowledge was in tune with the findings from Study 1 and supported $\mathrm{H}_{1}$ as well. However, in a less controlled setting, previous knowledge alone did not affect post-decision information search because other variables, such as the interaction term and cognitive dissonance, might have suppressed its effect. It is important to note that the maximizing tendencies alone did not exert any effect on post-decision information search, but its interaction with previous knowledge does affect the dependent variable. This effect is supported by Studies $2 \mathrm{~A}$ and $2 \mathrm{~B}$.

In Study 2A, we found no significant effect for the lowest levels of the maximizing tendencies as we did in Study $2 B$. In Study $2 B$, the floodlight analysis showed when the main effect changes its sign. For satisficers, the effect of previous knowledge on information search was negative, yielding marginally significant effects at the lowest levels of maximization. Thus, post-experience information search is reduced for knowledgeable participants with low maximizing tendency (i.e, the satisficers). For satisficers, their choices are usually in tune with their expectations (Schwartz et al., 2002). Thus, when they find an option that conforms to their parameters, they settle for it and are unlikely to engage in postpurchase behaviors (Ma \& Roese, 2014), such as information search. To the extent that satisficers held knowledge about their purchases and can experience their purchased product, as in Study $2 B$, they might be unlikely to search for more information about their purchases.

Furthermore, cognitive dissonance significantly increased the explanatory capacity of the model in Study 2A. In Study 2B, we replicated this finding with a different scale for cognitive dissonance. This result is in tune with previous studies (e.g., Ehrlich et al., 1957 Sweeney et al., 2002), even though such studies did not empirically investigate the effect of cognitive dissonance on post-decision information search. Thus, Studies $2 \mathrm{~A}$ and $2 \mathrm{~B}$ contribute to the preliminary understanding of the real effects of cognitive dissonance on post-decision information search. It is worth noting that satisfaction did not have a significant effect on the dependent variable. However, this result is not conclusive because we tested this variable in only one study.

\section{CONCLUSION}

In this study, we investigated the effects of consumers' previous knowledge, its interaction with maximizing tendencies, and the effects of cognitive dissonance and satisfaction on post-decision information search. In Study 1, we showed that individuals holding objective previous knowledge before making a choice searched for more information related to the available options after they made their decision and could not change it anymore. Studies $2 \mathrm{~A}$ and $2 B$ reinforced findings from Study 1 with a new type of previous knowledge (subjective knowledge) and explored the moderation effect of the maximizing tendencies and influence of cognitive dissonance. We found that, in non-controlled settings, previous knowledge had a significant effect when additional predictors were introduced into the regression model. The results showed 
an interaction wherein maximizers were more likely to search for information after making their final choice as a function of their previous knowledge.

This research has several theoretical contributions. First, it sheds light on consumers' previous knowledge as a new predictor of information search behavior. Hence, it advances the literature on post-decision information search. Second, to the best of our knowledge, this study is the first to show the effect of the interaction between previous knowledge and maximizing tendencies on post-decision information search. Thus, it also contributes to the literature on maximizing tendencies, especially considering that only few studies have explored the effects of this trait on behaviors elicited at the post-decision stage (Ma \& Roese, 2014). Third, the research advances the theory on the empirical effect of cognitive dissonance on post-decision information search. Again, to the best of knowledge, previous studies have not tested this effect. Fourth, we holistically analyzed consumer behavior, following suggestions from Lemon and Verhoef (2016), as we linked different stages of the customer journey by investigating a variable elicited at the pre-purchase stage (i.e., consumers' previous knowledge) that in affects consumer behavior at the post-purchase stage (i.e., information search).

Our study presents managerial implications as well. Consumers' knowledge may be a concern for business companies because consumers seek more information about goods and services before purchasing, being more knowledgeable than the sales person as well as more empowered by the knowledge they have (Gensler, Neslin, \& Verhoef, 2017). Through three studies, we show that knowledgeable consumers continue searching for more information about the products they have purchased. This way, marketers should assist consumers in this task. For instance, companies can provide more information about the purchased product (e.g., reinforce consumers' decision and give tips about how to use the purchased product, which may improve their experience with it) a few hours or days after the consumer has made a purchase. Furthermore, the information consumers find after a choice may serve as a "calibrating element" for their judgements. This may exert further influence on variables that are important for marketing performance, such as satisfaction and repurchase intentions (Shani \& Zeelenberg, 2007). If business companies provide to consumers more information at the post-purchase stage, they might have more control under the information consumers are accessing.

We also present approaches used by consumers to search for information at the post-purchase phase. If retailers know where consumers search for information, they can choose the best approach to reinforce consumers' decision, and, consequently, diminish back-out behaviors (Donelly \& Ivancevich, 1970) and feelings of regret (Shani \& Zeelenberg, 2007).

Finally, our study is not without limitations. First, we could not replicate the findings from Study 1 across Studies $2 \mathrm{~A}$ and $2 B$. Nevertheless, we found a marginal significant effect of previous knowledge in the model at level 3 after introducing the maximizing tendencies, the interaction term, and cognitive dissonance. This may indicate the suppression effect of other variables (Mackinnon et al., 2000) when we investigate consumers' previous knowledge in a more naturalistic condition. Across the three studies, the effect of previous knowledge has the same direction as we proposed in $\mathrm{H}_{1}$. Second, in Study $2 \mathrm{~B}$, we did not measure feelings of regret, which may increase or decrease information search behavior (Shani \& Zeleenberg, 2007). We used a scale to measure satisfaction, which may be an indicator of individuals' feelings of regret, but it is not a measure of it. Finally, we did not explore the effects of postdecision information search on participants' satisfaction with the decision and their repurchase intentions. Further studies should investigate these variables because they are important to improve marketing performance (Brega, 2018).

This research amplifies the understanding of consumers' post-decision experience, diverging from previous marketing literature that focuses mainly on variables such as satisfaction, repurchase intention, and service failures topics (e.g., Bach \& Kim, 2012; Wirtz et al., 2007). Differently from this literature, we investigated the post-decision information search behavior, which may strongly affect consumers' actions toward brands, goods, and services (Oliver, 2014).

\section{NOTE OF APPRECIATION}

We would like to thank CAPES for the financial support to research.

\section{REFERENCES}

Alba, J. W., \& Hutchinson, J. W. (2000). Knowledge calibration: What consumers know and what they think they know. Journal of Consumer Research, 27(2), 123-156. doi: doi.org/10.1086/314317

Ali, F. (2019). U.S sales grow 15.0\% in 2018. Recuperado de https:// www.digitalcommerce360.com/article/us-ecommerce-sales/

Bach, S. B., \& Kim, S. (2012). Online consumer complaint behaviors: The dynamics of service failures, consumers' word of mouth, and organization-consumerrelationships.InternationalJournalofStrategic Communication, 6(1), 59-76. doi: 10.1080/1553118X.2011.634871 
Bettman, J. R, \& Park, C. W. (1980). Effects of prior knowledge and experience and phase of the choice process on consumer decision processes: a protocol analysis. Journal of Consumer Research, 7, 234248. doi: $10.1086 / 208812$

Brega, J. (2018). O sucesso da Whirlpool crescendo em qualquer contexto. Retrieved from: https://www.mckinsey.com.br/ourinsights/blog-made-in-brazil/o-sucesso-da-whirlpool-crescendoem-qualquer-contexto/

Brucks, M. (1985). The effects of product class knowledge on information search behavior. Journal of Consumer Research, 12, 1-16. doi: 10.1086/209031

Carlson, J. P., Vincent, L. H., Hardesty, D. M., \& Bearden, W. O. (2009). Objective and subjective knowledge relationships: a quantitative analysis of consumer research findings. Journal of Consumer Research, 35, 864-876. doi: 10.1086/593688

Chu, S. C., \& Kim, Y. (2011). Determinants of consumer engagement in electronic word-of-mouth (eWOM) in social networking sites. International Journal of Advertising, 30(1), 47-75. doi: 10.2501/ ija-30-1-047-075

Delloite. (2017). 2017 Global Mobile Consumer Survey: US edition. Retrieved from https://www2.deloitte.com/content/dam/Deloitte/ us/Documents/technology-media-telecommunications/us-tmt2017-global-mobile-consumer-survey-executive-summary.pdf

Dholakia, N., Zwick, D., \& Denegri-Knott, J. (2013), Technology, consumers and marketing theory. In P. Maclaran, M. Saren, B. Stern, \& M. Tadajewski (Eds.), The Sage handbook of marketing theory (pp. 494-511). London, UK: Sage.

Donelly, J. H., \& Ivancevich, J. M. (1970). Post-purchase reinforcement and back-out behavior. Journal of Marketing Research, 7, 399-400. doi: $10.2307 / 3150746$

Ehrlich, D., Guttman, I., Schönbach, P., \& Mills, J. (1957). Postdecision exposure to relevant information. The Journal of Abnormal and Social Psychology, 54(1), 98. doi: 10.1037/hoo42740

Field, A. \& Graham, H. (2003). How to design and report experiments. London, UK: Sage.

Field, A. (2013). Discovering statistics using IBM SPSS. London, UK: Sage.

Gensler, S., Neslin, S. A., \& Verhoef, P.C. (2017). The showrooming phenomenon: It's more than just about price. Journal of Interactive Marketing, 38, 29-43. doi: 10.1016/j.intmar.2017.01.003

Goldsmith, K., Roux, C., \& Ma, J. (2018). When seeking the best brings out the worst in consumers: Understanding the relationship between a maximizing mindset and immoral behavior. Journal of Consumer Psychology, 28(2), 293-309. doi: 0.1002/jcpy.1017

Hadar, L., Sood, S., \& Fox, C. R. (2013). Subjective knowledge in consumer financial decisions. Journal of Marketing Research, 50(3), 303-316. doi: 10.1509/jmr.10.0518

Hayes, A. (2013). Introduction to mediation, moderation, and conditional process analysis: A regression-based approach. New York City, NY: The Guilford Press New York.
Hennig-Thurau, T., Gwinner, K. P., Walsh, G., \& Gremler, D. D. (2004). Electronic word-of-mouth via consumer-opinion platforms: What motivates consumers to articulate themselves on the Internet? Journal of Interactive Marketing, 18(1), 38-52. doi: 10.1002/dir.10073

Iyengar, S. S, Wells, R. E., \& Schwartz, B. (2006). Doing better but feeling worse. Psychological Science, 17, 143-150. doi: 10.1111/j.1467 9280.2006.01677.x

Jones, E. H. (2002). A cognitive dissonance theory perspective on persuasion. In J. Dillard, M. Pfau (Eds.), The persuasion handbook: Developments in theory and practice (pp. 99-117). CA: SAGE Publications.

Kemp, S. (2018). Digital in 2018: World's internet users pass the 4 billion mark. Retrieved from https://wearesocial.com/blog/2018/o1/ global-digital-report-2018/

Kiel, G. C., \& Layton, R. A. (1981). Dimensions of consumer information seeking. Journal of Marketing Research, 18, 233-239. doi: $10.1177 / 002224378101800210$

Lee, H. H., \& Kim, J. (2008). The effects of shopping orientations on consumers' satisfaction with product search and purchases in a multi-channel environment. Journal of Fashion Marketing and Management: An International Journal, 12(2), 193-216. doi: 10.1108/09590550910934272

Lemon, K.N., \& Verhoef, P. C. (2016). Understanding customer experience throughout the customer journey. Journal of Marketing, 8o(6), 69-96. doi: 10.1509/jm.15.0420

Luan, M., \& Li, H, (2017). Maximization paradox: result of believing in an objective best. Personality and Social Psychology Bulletin, 43(5), 652-661. doi: 10.1177/0146167217695552

Ma, J., \& Roese, N. J. (2014). The maximizing mind-set. Journal of Consumer Research, 41, 71-92. doi: 10.1086/674977

MacKinnon, D. P., Krull, J. L., \& Lockwood, C. M. (2000). Equivalence of the mediation, confounding and suppression effect. Prevention Science, 1(4), 173-181.

Mehra, A., Kumar, S., \& Raju, J. S. (2017). Competitive strategies for brick-and-mortar stores to counter "showrooming." Management Science, 64(7), 3076-3090. doi: 10.1287/mnsc.2017.2764

Mittal, B. (1989). Measuring purchase-decision involvement. Psychology \& Marketing, 6(2), 147-162. doi: 10.1002/mar.4220060206

Montgomery, C., \& Barnes, J. H. (1993). POSTDIS: A short rating scale for measuring postpurchase dissonance. Journal of Consumer Satisfaction, Dissatisfaction and Complaining Behavior, 6, 204-216.

Oliver, R. L. (2014). Satisfaction: A behavioral perspective on the consumer. New York City, NY: Routledge.

Park, C. W., Monthersbaugh, D. L., \& Feick, L. (1994). Consumer knowledge assessment. Journal of Consumer Research, 21(1), 71-82. doi: $10.1086 / 209383$

Punj, G. N., \& Staelin, R. (1983). A model of consumer information search behavior for new automobiles. Journal of Consumer Research, 9(4), 366-380. doi: 10.1086/208931 
Raju, P. S., Lonial, S. C., \& Mangold, W. G. (1995). Differential effects of subjective knowledge, objective knowledge, and usage experience on decision making: An exploratory investigation. Journal of Consumer Psychology, 4(2), 153-180. doi: 10.1207/s15327663jcp0402_04

Redação Forbes (2018). Compras online somaram R\$166.2 bi no Brasil. Retrieved from https://forbes.uol.com.br/colunas/2018/09/ compras-online-somaram-r-1662-bi-no-brasil/

Schwartz, B., Ward, A., Monterosso, J., Lyubomirsky, S., White, K., \& Lehman, D. R. (2002). Maximizing versus satisficing: Happiness is a matter of choice. Journal of personality and social psychology, 83(5), 1178-1197. doi: 10.1037//0022-3514.83.5.1178

Shani, Y., \& Zeelenberg, M. (2007). When and why do we want to know? Experienced regret promotes post-decision information search. Journal of Behavioral Decision Making, 20(3), 207-222. doi: 10.1002/bdm.550

Simon, H. A. (1956). Rational choice and the structure of the environment. Psychological Review, 63(2), 129. doi: 10.1037/hoo42769
Spiller, S. A., Fitzsimons, G. J., Lynch, J. R., \& McClelland, G. H. (2013). Spotlights, floodlights, and the magic number zero: Simple effects tests in moderated regression. Journal of Marketing Research, 50(2), 277-288. doi: 10.1509/jmr.12.0420

Sweeney, J. C., Hausknecht, D., \& Soutar, G. N. (2000). Cognitive dissonance after purchase: A multidimensional scale. Psychology and Marketing, 17, 369-385. doi: 10.1002/(SICI)15206793(200005)17:5‘369::AID-MAR1)3.0.CO;2-G

Teodorescu, K., Sang, K., \& Todd, P. M. (2018). Post-decision search in repeated and variable environments. Judgment \& Decision Making, 13(5). doi: 18/18202/jdm18202

Wirtz, J., Mattila, A. S., \& Tan, R. L. (2007). The role of arousal congruency in influencing consumers' satisfaction evaluations and in-store behaviors. International Journal of Service Industry Management, 18(1), 6-24. doi: 10.1108/09564230710732876

\section{AUTHORS' CONTRIBUTIONS}

The authors declare that they contributed equally in the paper development, conceptualization and theoretical-methodological construction, theoretical revision, writing and finally, revising the manuscript. The theoretical review (literature survey) was conducted by first author and supervised by the second author. 